\title{
Study on the Transformation and Application of Japanese Loanwords in Chinese
}

\author{
Tian Zeng \\ Shanghai Xingjian College Zeng Tian(China,Shanghai200072)
}

Keywords: Japanese Loanwords; Chinese; Cultural exchange

\begin{abstract}
The cultural exchanges between China and Japan led to innovation of language and culture, especially the development of network technology makes cultural exchanges be more convenient, and Japanese loanwords had a profound impact on the development of Chinese gradually. In the process of understanding and analysis of the transformation and application of Japanese Loanwords in Chinese in recent years can understand the history of cultural exchange.

The traditional idea thinks that Japan culture is influenced by Chinese culture, Japanese and Chinese are inextricably linked in vocabulary, pronunciation, text and other aspects, but in the cultural exchanges of China and Japan, people tend to fall into a misunderstanding thinking Japanese culture influenced by Chinese culture in single aspect, not to know the culture communication is the mutual influence, although the Japanese formed by the Chinese, but in the process of Japanese development, it will in turn enrich and influence the process of the development of Chinese.
\end{abstract}

\section{The Origin and Main forms of Japanese Loanwords in Chinese}

Firstly, the source of Japanese Loanwords in Chinese are rich and varied. The source of Japanese Loanwords introduced into the Chinese language and culture are complex, not only the source of Japanese Loanwords are very diverse, the introduction of Chinese Loanwords in Japanese sources is also the case.

A source of Japanese Loanwords is the ancient Chinese culture, with a lot of economic and cultural exchanges between ancient China and Japan, promoting some of the words and the way of life into Japan, and in Japan, after hundreds or even thousands of years after evolution leads to the meaning and pronunciation changed, so the Japanese Loanwords from Chinese in turn when may cause people to understand the ambiguity. A part of Japanese Loanwords from Japanese in the formation of unique social culture as Japanese words, and some from the western culture in Meiji Restoration Period and with the evolution of the local reference to the word, this kind of words can often reflect the formation of unique cultural environment of the words.

Peaks of introduction of Japanese Loanwords are mainly concentrated in the late Qing Dynasty and the Reform and Opening up Period, and in the late Qing Dynasty, the nature of our society changes dramatically at the same time, while Japan studied a lot of advanced technology and culture in Meiji Restoration Period, since the Chinese and Japanese cultural and geographical distance are similar, there are many scholars have chosen to go to Japan to study in order to save the massive wave of Japan led the Japanese advanced culture and Japanese into China, many Japanese books in person after translation went into China, but due to the specific historical conditions' effect, the Japanese Loanwords in this period in politics, economy and law, such as liberation, science and other words. After the 1978, the Reform and Opening up made the development of information network technology in China have led to the Japanese popular culture and cultural exchanges in China, especially Chinese young groups affected by the Japanese cartoon industry and game industry, and many Japanese words gradually become the popular language of network for young generation, such as the popular "fag hag" and "Indoors man" are highly influenced by the Japanese culture. Not only that, along with the two countries in political, economic and cultural exchanges have become increasingly close, many Japanese nouns also become an indispensable part of the Chinese, such as "just in time", "easy"and other phrases are from Japanese.[1] 
Secondly, there are many kinds of Japanese Loanwords in Chinese. Some Japanese Loanwords and Chinese words have the original shape but not synonymous, the Japanese Loanwords in Chinese can be transformed into the identification and reading, but its meaning is often vary greatly with Chinese, such as "arrange" (料理) is a word originally in Chinese for taking care of somebody or arrangement, but due to the large number of Japanese cuisine and cuisine culture brought into China, "food" (料理) in Chinese has another layer of meaning. Some Japanese Loanwords tend to become Chinese morpheme or grammatical changing traditional Chinese way of expression, for example, now people call a group often defined by "characteristics + family" form, including starstruck family, otaku family, moonlight family and so on, the call of "family" comes from Japanese which transformed into Chinese referring to a group of morpheme composition. The application of these forms of Japanese Loanwords in Chinese has greatly enriched the meaning of Chinese vocabulary and made easier to carry out cultural exchanges between the two cultures.[2]

\section{The Influence of the Transformation and Application of Japanese Loanwords in Chinese on Chinese Culture}

In the cultural exchanges between the two countries, Japanese culture and Chinese language and culture are constantly used for reference and development, Japanese Loanwords into Chinese can have a great impact on Chinese language and culture from the following aspects

Firstly, Japanese Loanwords can enrich the meaning of Chinese and promote the development of Chinese language. Chinese can absorb many of the original system of language vocabulary and mastery for their own use, the number of Chinese words and meaning can extend the original Chinese vocabulary, and is conducive to the public understanding of Japanese culture in the process of transformation in foreign words. The Japanese Loanwords in Chinese will have a significant impact on original morphemes and word formation grammar, such as "in the period of" means "moving" in Japanese, while it has no similar meaning in Chinese. After "in the period of" introduced into Chinese, it changes Chinese original expression, such as the "doing business" or "taking a break" may be transformed into "in the period of business "and "in the period of rest" in this way of expression, and the expression of the original Chinese grammar is different, with this morpheme or grammatical use derived expression, Japanese Loanwords derive many novel Chinese words.

In a large part of Japanese Loanwords become prefix or suffix in Chinese expression, extending the Chinese way of expression, such as mentioned of mode of expression" XX family", as well as "super + expressions" now become daily and the expression of a group or some kind of feeling to people. It can be seen that the Japanese Loanwords in Chinese have an important role in enriching the connotation of Chinese and expanding the scope of expression.

Secondly, the effective transformation of Japanese Loanwords can promote cultural exchanges between Chinese and Japanese. As a part of Japanese culture, Japanese Loanwords in Chinese in the application and transformation are implemented in two kinds of cultural exchanges, so Japanese Loanwords in Chinese can promote the absorption of two kinds of cultural exchanges between the two sides and understanding to actively learn culture and desirable place together. These Japanese Loanwords can go deep into every field of people's life and work, which are widely used in people's life and foreign exchanges that can not only enrich the Chinese language and culture and Japanese, but also can lead the Chinese users to understand the Japanese culture, and with the Japanese Loanwords to understand Japanese culture and Japanese expressions can increase the respect in culture and Japanese speakers, reduce cultural barriers. Friendly exchanges in Japanese and Chinese not only need to learn a language, but also to learn from each other for common development, actively introduce in Japanese Loanwords in Chinese can play an important role in promoting cultural exchange and language development.

Thirdly, the use of Japanese Loanwords also have a negative impact. The coexistence of essence and dross in culture means there are also some Japanese do not conform to the time development which should be rejected, if the introduction of Japanese Loanwords in Chinese not carefully be 
distinguish and it will cause some dross culture into the local culture to accept the other poison, some decadent does not conform to the trend of social development or negative culture of the words in Chinese will lead to negative effect of incoming, the visit has not yet fully formed youth development that plays a key role. On the other hand, in a large number of Japanese Loanwords into Chinese changing people's traditional way of expression at the same time, because the Japanese Loanwords tend to be accepted by younger audiences, the media is the main network technology, leading some conservative old people unable to keep pace with the trend of development, and easy to arise communication barriers and cultural confusion phenomenon by using the Japanese Loanwords.[3]

\section{Suggestions on the Use and Transformation of Japanese Loanwords in Chinese}

In recent years, the Chinese and Japanese cultural exchanges increasingly close makes more Japanese Loanwords brought into Chinese culture, which should be taken seriously in its reasonable application and transformation, taking into account the culture has double effect and consider whether to refer to the foreign language, the following is the suggestion of application of Japanese Loanwords.

Firstly, actively absorb the new cultural expression, and promote the friendly exchanges between the two cultures. Japanese Loanwords into Chinese can promote the common development of the two languages, expanding the Chinese way of expression and meaning of vocabulary, and it can use Japanese Loanwords to make both understand the words when communicating with Japanese speakers to make closer exchanges distance and promote two types of cultural communication. Sometimes the Chinese grammar and morphemes are not commonly used will cause the expression more jumbled, actively adopt application can effectively simplify the communication process of expansion of the Chinese language expression convenient expressions in Japanese. So some Japanese Loanwords can have a positive effect on the Chinese language and culture into China, which should actively use these new ways of expression that can understand Chinese interpretations of some Japanese loanwords, and actively promote the benign cultural exchanges between the two countries.

Secondly, rational use and have correct view of Japanese Loanwords. Japanese Loanwords in Chinese can be transformed and applied often depends on whether it is beneficial to Chinese expression, and therefore accept the unique words in Japanese Chinese meaning also should be selected, some Japanese Loanwords which will cause many misunderstandings should be reduced, and that with negative meaning should be to resist in order to not let the negative influence of Chinese culture. Used to treat Japanese Loanwords should do not disable nor abuse those biases on Japan's people should not blindly boycott Japanese loanwords, it means users should recognize Japanese Loanwords as a product of cultural exchanges between the two countries that will inevitably appear on Japanese Loanwords, while good and useful should be accepted. But some young people that keen on network culture can't abuse the Japanese Loanwords in real life, especially communicating with some older people, they should consider older people do not understand some popular words, and some Japanese Loanwords that easily lead to ambiguity should reduce the use for young people affected by the Japanese comic, but not because of have more contact with the blind worship of other cultural phenomena, and it should have a reasonable view of each culture by respecting for cultural differences and seeking common ground. [4]

Based on the above analysis of three aspects of Japanese Loanwords in Chinese, transformation and the use of two languages is a normal phenomenon in the process of cultural exchange, but we should pay attention to the cultural characteristics of the two-way influence in reference to Japanese Loanwords, rational use of Japanese loanwords to express themselves in the life and work, to promote the development of the Chinese culture the transformation and application of Japanese Loanwords in Chinese language and culture promoting the two kinds of mutual exchange and common progress. 


\section{References}

[1]Hui Li,Xiaohe Zhao.The influence of Japanese Loanwords in Chinese[J].Intelligence, 2015 ( 12) [2]Xiao Li.The function and influence of Japanese Loanwords in Chinese in recent years[J].Modern Economic Information, 2016 (06)

[3]Xun Sun.On the etymology of Japanese Loanwords in modern Chinese[J].Foreign Language Teaching, 2015 (03)

[4]Yueyu Huang.Study on Japanese Loanwords in modern Chinese[J].Read and Write Magazines, $2012(04)$ 